\title{
Epidemiologic Assessment of the Protective Effects of Smallpox Vaccination
}

\author{
${ }^{1,2}$ Hiroshi Nishiura, ${ }^{3}$ Isao Arita, ${ }^{1}$ Markus Schwehm and ${ }^{1}$ Martin Eichner \\ ${ }^{1}$ Department of Medical Biometry, University of Tübingen, Tübingen, Germany \\ ${ }^{2}$ Research Center for Tropical Infectious Diseases \\ Nagasaki University Institute of Tropical Medicine, Nagasaki, Japan \\ ${ }^{3}$ Agency for Cooperation in International Health, Kumamoto, Japan
}

\begin{abstract}
Despite smallpox eradication, the widely discussed possibility of a bioterrorist attack using a variola virus makes it necessary to review the epidemiology of smallpox and the effects of various vaccination schemes. This paper provides a literature review concerning the epidemiologic assessment of the protective effects of smallpox vaccination, with particular emphasis on the statistical and theoretical points of view. Although smallpox vaccination has the longest history of all vaccinations, we lack precise epidemiologic estimates of its effectiveness. Vaccination practice continually evolved and many places experienced vaccinations with various strains over time. Despite the weak statistical evidence, it can be stated with certainty that smallpox vaccines prevented infection for a few decades after primary vaccination and that vaccinated individuals had the benefit of a longer lasting partial protection when they contracted the disease. Confronted with the huge uncertainties and with the necessity to rely on laboratory evidence, appropriate preparedness plans for countermeasures using vaccination must be based on the best available evidence.
\end{abstract}

Key words: Smallpox, variola virus, vaccination, epidemiology, bioterrorism

\section{INTRODUCTION}

Smallpox is the only infectious disease that has been eradicated through concerted efforts ${ }^{[1,2]}$ and thereby provides one of the biggest success stories of immunization and public health efforts ${ }^{[3]}$. Despite its eradication, the widely discussed possibility of a bioterrorist attack using a variola virus makes it necessary to review the epidemiology of smallpox and the effects of various vaccination schemes ${ }^{[4]}$. There has never been a population-based evaluation of the effectiveness of smallpox vaccination (e.g., a randomized controlled trial). Being the first disease against which a vaccine became available ${ }^{[2]}$, some of the earliest epidemiologic vaccination studies were performed on smallpox and both epidemiologic and statistical methods matured in parallel as new clinical and epidemiological observations were made ${ }^{[5,6]}$. Thus, from a contemporary point of view, some of these pioneering epidemiologic assessments of the protective effects of vaccination should be regarded as technically flawed or exaggerated ${ }^{[7]}$.

Some of the best insights in the effects of widespread vaccination can be gained from the technical and political discussions and the earliest epidemiologic observations on compulsory vaccination in the late 19th and early 20 th century ${ }^{[8,9]}$. To evaluate the impact of vaccination on the epidemiology of smallpox, statistical evidence, especially on the protective effect of primary vaccination, was extensively accumulated during that period ${ }^{[7]}$. During the Smallpox Eradication Programme intensified since 1967, considerable efforts were undertaken to evaluate alternative vaccination strategies (e.g., post-exposure and ring vaccinations). Now that we do not see any smallpox cases and are not allowed to perform challenge inoculations, population-based estimates of the protective effects can only be obtained through the investigation of such epidemiologic data. This paper provides a literature review concerning the epidemiologic assessment of the protective effects of smallpox vaccination, with particular emphasis on the statistical and theoretical points of view.

Different vaccines and efficacy: As several different kinds of vaccine were used ${ }^{[2]}$, statistical records of smallpox vaccination must be interpreted with caution. Variolae vaccine, for example, can either denote the vaccine first developed by Jenner for cowpox ${ }^{[10]}$ or one of the vaccine strains obtained from the 'retrovaccination' technique which was primarily effected by taking the variola virus from human lesions back to a cow, yielding a vaccine of relatively low potency ${ }^{[11]}$. We know neither the origins of the vaccinia virus nor the time of its introduction ${ }^{[12]}$. During the Smallpox Eradication Programme, highly potent vaccines were introduced whose immunogenicity was evaluated using pock counts, but prior vaccines usually did not undergo any strict evaluations ${ }^{[13]}$. These facts indicate the necessity to assume that the vaccine efficacy may have changed over time.

The efficacy of smallpox vaccination, i.e. the extent to which application of a specific vaccine produced a beneficial result in a population, also differs from the direct effectiveness (i.e. the word 'efficacy' of smallpox vaccine was frequently used to indicate

Corresponding Author: Dr. Hiroshi Nishiura, Department of Medical Biometry, University of Tübingen, Westbahnhofstr. 55, Tübingen, D-72070, Germany, Tel: +4970712973405, Fax: +497071295075 
potency or individual-based successful vaccination $)^{[14]}$. Traditionally, the efficacy of smallpox vaccination was measured by the 'take' rate which was determined by an observation of a pustular lesion at the injection site 6 to 10 days after vaccination ${ }^{[15]}$. Since the localized infection that expressed itself as the vaccine 'take' lesion was also interpreted as the generation of an immune response, the sign was gradually accepted as a method to determine the vaccine's efficacy ${ }^{16,17]}$. In contrast, most recent laboratory-based techniques interpret specific immune responses as measure of immunogenicity and protection ${ }^{[17,18]}$.

\section{Effectiveness of primary vaccination}

Early epidemiologic observations: In the period which followed Jenner's discovery of the variolae vaccine in the late 18 th century ${ }^{[10]}$, the evidence of the protective effect of vaccination mostly depended on "minute inquiry into individual cases" ${ }^{\text {" } 7]}$. With a few noteworthy exceptions, statistical reports from the early 19th century give only approximate numbers of cases by vaccination history, which were often based on somewhat unclear definitions and which in general tended to exaggerate the effectiveness of vaccination ${ }^{[19,20]}$. By the end of the 19th century, the need arose to accumulate comprehensive evidence on the 'protectiveness of vaccination' in order to convince the public of the benefits of compulsory vaccination ${ }^{[7,21]}$. Comparisons of the situation before and after the introduction of voluntary or compulsory vaccination or of places with and without vaccination painted a rather crude picture, but sufficed to demonstrate the general benefits of vaccination ${ }^{[22]}$. One of the oldest assessments of the impact of vaccination shows the smallpox death rate in time series from Sweden during 18th and 19th centuries (Fig. 1) ${ }^{[22-24]}$.

Protection against disease and death: Despite the impressive decline in incidence after the introduction of vaccination, considerable discussion arose on the evidence of such historical and geographical comparisons, attacking the often highly overstated vaccine effects ${ }^{[21]}$. To accumulate data that more directly reflected the effect of vaccination, it gradually became customary to perform comparisons within the same outbreak ${ }^{[7]}$ : the case fatality of vaccinated cases was compared with that of unvaccinated ones. This shift in the way epidemiologic observations were performed also changed the viewpoint on the protective effect of vaccines ${ }^{[2,7]}$. Whereas the population-based observations had crudely measured the protection against smallpox (direct effectiveness) that also included some effect on herd immunity, the observations based on defined case-cohorts allowed to examine the vaccine's partial protection ${ }^{[5,7]}$. These studies demonstrated that the probability of dying from smallpox was strongly reduced for vaccinated cases (Fig. 2). Table 1 compares crude estimates of the direct effectiveness of vaccination (as proposed by Greenwood and Yule ${ }^{[25]}$ ) and also includes some of the earliest findings available.

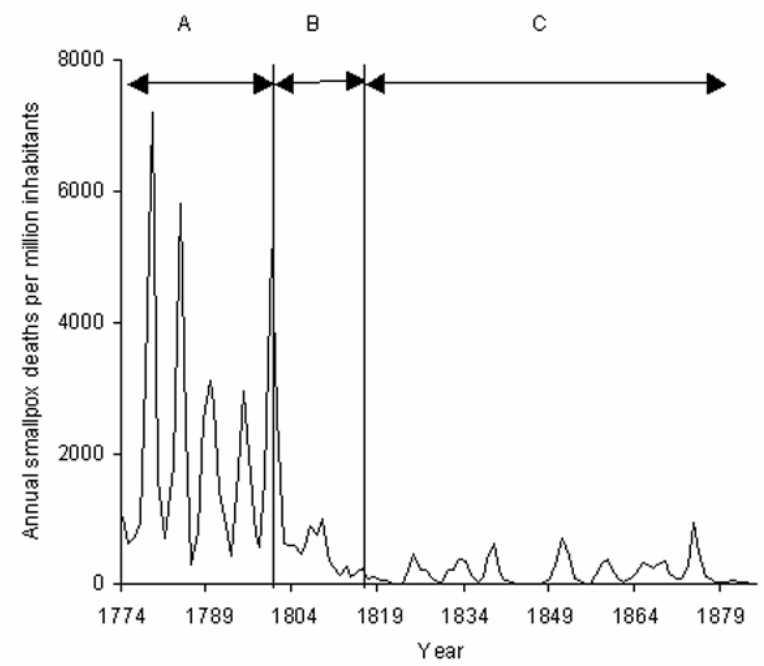

Fig. 1: Annual reported number of smallpox deaths per million inhabitants in Sweden from the late 18th to 19th century. A: Before introduction of vaccination, B: After introduction of vaccination, $\mathrm{C}$ : After introduction of compulsory vaccination (for original data ${ }^{[22,23]}$ )

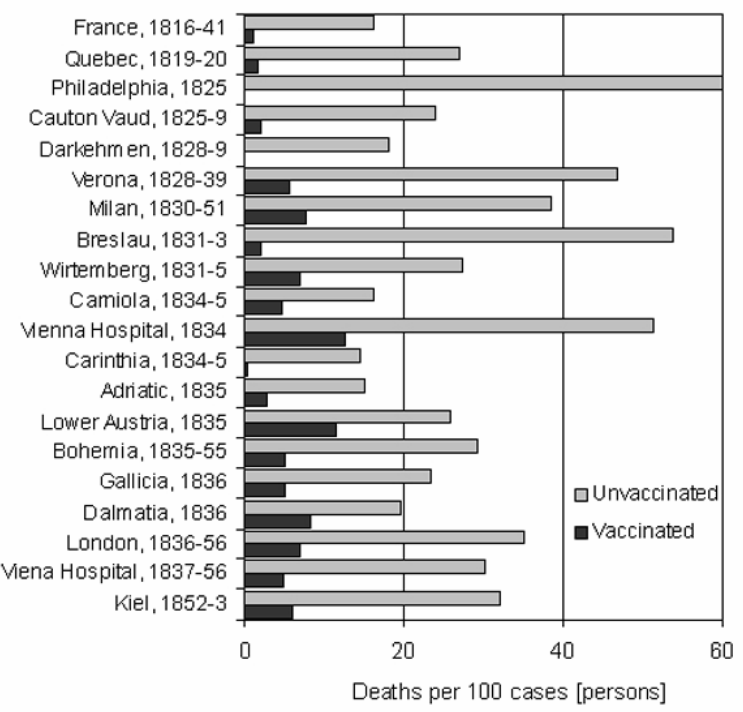

Fig. 2: Comparisons of the case fatality proportions of smallpox by vaccination status in Europe during early 19th century. For original descriptions of the data ${ }^{[7,19,91-93]}$

Population-based evaluations of the protection against disease unfortunately are relatively rare compared to investigations on the partial protection of cases (Table 1). In the study in Norwich, in 1819 , the numbers were based on direct observations of 112 families ${ }^{[26]}$. Whereas the numbers for Marseilles (1828) are lacking precision ${ }^{[20]}$, similar studies comparing the 'attack rates' (which now would be called incidence) were gradually 
Am. J. Infect. Dis., 2(1): 9-17, 2006

Table 1: Crude estimates of the direct effectiveness of smallpox vaccination

\begin{tabular}{|c|c|c|c|c|c|c|}
\hline \multirow[t]{2}{*}{ Place (reference) } & \multicolumn{2}{|c|}{ Vaccinated } & \multicolumn{2}{|c|}{ Unvaccinated } & \multicolumn{2}{|c|}{ Crude effectiveness } \\
\hline & $\mathrm{N}^{\#}$ & Cases & $\mathrm{N}^{\#}$ & Cases & Expected & $95 \% \mathrm{CI}^{\S}$ \\
\hline \multicolumn{7}{|l|}{ Before $^{\dagger}$} \\
\hline Norwich, England, $1819^{[26]}$ & 91 & 2 & 215 & 200 & $97.5 \%$ & $90.5,99.4$ \\
\hline Marseilles, France, $1828^{[20]}$ & 30000 & 2000 & 8000 & 4000 & $86.7 \%$ & $85.9,87.4$ \\
\hline Sheffield, England, 1887- $8^{[50]}$ & 307966 & 4995 & 6556 & 1028 & $89.7 \%$ & $88.9,90.3$ \\
\hline Fitchburg, MA, USA, 1931-2 $2^{[90]}$ & 114 & 3 & 79 & 57 & $96.3 \%$ & $88.3,98.9$ \\
\hline \multicolumn{7}{|l|}{ After ${ }^{\ddagger}$} \\
\hline Brazil (Nationwide), 1967-69 ${ }^{[31]}$ & 423 & 18 & 1376 & 1010 & $94.2 \%$ & $90.8,96.4$ \\
\hline Bahia, Brazil, $1969^{[30]}$ & 113 & 4 & 354 & 242 & $94.8 \%$ & $86.1,98.0$ \\
\hline Brazil (Nationwide), $1969^{[32]}$ & 513 & 17 & 1937 & 1475 & $95.6 \%$ & $93.0,97.3$ \\
\hline Punjab, West Pakistan, 1968-70 $0^{[28]}$ & 52 & 3 & 390 & 83 & $72.9 \%$ & $14.2,91.4$ \\
\hline Calcutta, India, 1972-3 Single family ${ }^{[29]}$ & 93 & 9 & 18 & 13 & $86.6 \%$ & $68.7,94.3$ \\
\hline Calcutta, India, 1972-3 Multiple family ${ }^{[29]}$ & 568 & 38 & 62 & 48 & $91.4 \%$ & $86.8,94.4$ \\
\hline
\end{tabular}

accumulated $^{[21]}$. Based on a similar point of view, a recent study confirmed that vaccination reduced the risk for death among pregnant smallpox cases ${ }^{[6]}$.

Direct effectiveness during the eradication programme: The Smallpox Eradication Programme accepted many different vaccination schedules (e.g. revaccination, post-exposure vaccination, ring vaccination etc.), which makes it difficult to estimate the effectiveness of vaccination after World War II (Table 1). As vaccination efforts always coincided with other countermeasures like isolation or quarantine, crude estimates on the direct vaccination effectiveness may be biased ${ }^{[2]}$. On the other hand, technical improvements in epidemiologic methods included the consideration of transmission within households ${ }^{[27-29]}$ and the adjustment for age ${ }^{[30]}$. Some of the latest estimates of the direct effectiveness of vaccination, obtained from outbreaks in Brazil ${ }^{[30-32]}$, demonstrated an extremely high effectiveness (Table 1). As the corresponding case fatalities were extremely low, these epidemics were considered as variola minor outbreaks. Therefore, the corresponding vaccine effectiveness may have been overestimated as mild cases among vaccinated individuals may have been under-diagnosed $^{[33]}$. Another crude estimate of $81.6 \%$ for the direct effectiveness $(95 \%$ confidence interval (CI): $64.4,92.2$ ) was obtained in a statistical study of a variola major outbreak in Nigeria, $1967^{[34,35]}$.

Indirect effectiveness during the eradication programme: A major development during the Eradication Programme was the consideration of herd immunity $^{[36]}$. Whereas Dixon had recommended vaccination and revaccination of the entire population at short intervals to achieve eradication ${ }^{[37]}$, it has been suggested that an indirect effectiveness of vaccination would predict eradication at a lower threshold ${ }^{[38]}$. It is noteworthy that, even during the 19th century, there were implicit discussions on such indirect effects $^{[23,24,39]}$.
The impact of population density on the eradication threshold during the Eradication Programme has been evaluated $^{[40]}$. Observations on population density and vaccination coverage in African and Asian countries showed that smallpox tended to disappear when the density of unvaccinated individuals fell below 10 persons per $\mathrm{km}^{2}$ whereas it was more likely to persist in densely populated regions ${ }^{[40]}$. Although nationwide estimates had indicated the requirement of rather higher vaccination coverage (i.e, more than $95 \%$ ) to eradicate smallpox by vaccination alone, this reflected the limitation of the crude estimate: Smallpox tended to die out in some rural areas even without vaccinations, whereas urban areas were likely to sustain the chain of transmission $^{[40]}$. Due to the frequent combination of vaccination with other intervention measures against the disease and because the disease was accompanied by obvious clinical symptoms, the net impact of vaccination on herd immunity could not be evaluated precisely ${ }^{[38]}$. Although the threshold condition was only clarified after eradication ${ }^{[41,42]}$, examination of an earlier recommendation by the WHO implies that the basic reproduction number, $R_{0}$, i.e., the average number of secondary cases per index case in a fully susceptible population, was assumed to be around 5, considering $80 \%$ of vaccination coverage as a goal ${ }^{[38,43]}$. This implicit estimate and the discussions on its variability were consistent with recent estimates ${ }^{[35,44,45]}$.

Loss of vaccine-induced immunity: The epidemiology of smallpox becomes even more difficult to interpret when we have a closer look at the waning protective effects of vaccination. It was recognized soon after the introduction of vaccination that vaccinated cases tended to be much older than unvaccinated ones ${ }^{[46,47]}$, which led to the idea that vaccine-induced protection waned over time ${ }^{[37]}$. Figure 3 allows to compare age-specific frequencies of vaccinated and unvaccinated cases in three outbreaks in the 19th and 20th centuries. 
Am. J. Infect. Dis., $x(x): x x-x x, 2006$

Table 2: $\quad$ Age dependent numbers of smallpox cases and deaths by vaccination status in Sheffield, 1887-8

\begin{tabular}{|c|c|c|c|c|c|c|c|c|}
\hline \multirow[t]{2}{*}{ Age } & \multicolumn{3}{|c|}{ Vaccinated } & \multicolumn{3}{|c|}{ Unvaccinated } & \multicolumn{2}{|c|}{ Direct effectiveness } \\
\hline & $\mathrm{N}$ & Cases & Deaths & $\mathrm{N}$ & Cases & Deaths & Expected & $95 \% \mathrm{CI}^{\S}$ \\
\hline$<1$ & 6047 & 10 & 0 & 1935 & 105 & 53 & $97.0 \%$ & $94.2,98.4$ \\
\hline $1-5$ & 32259 & 87 & 1 & 340 & 113 & 38 & $99.2 \%$ & $98.9,99.4$ \\
\hline $6-10$ & 39982 & 241 & 6 & 319 & 184 & 39 & $99.0 \%$ & $98.7,99.1$ \\
\hline $11-15$ & 37825 & 782 & 12 & 270 & 184 & 36 & $97.0 \%$ & $96.4,97.4$ \\
\hline $16-20$ & 31101 & 1240 & 26 & 323 & 196 & 56 & $93.4 \%$ & $92.4,94.3$ \\
\hline $21-25$ & 27296 & 950 & 45 & 477 & 129 & 51 & $87.1 \%$ & $84.5,89.3$ \\
\hline $26-30$ & 24088 & 616 & 40 & 537 & 39 & 13 & $64.8 \%$ & $51.3,74.5$ \\
\hline $31-35$ & 22353 & 403 & 33 & 366 & 33 & 14 & $80.0 \%$ & $71.5,86.0$ \\
\hline $36-40$ & 19078 & 265 & 28 & 387 & 23 & 10 & $76.6 \%$ & $64.2,84.7$ \\
\hline $41-45$ & 17220 & 164 & 19 & 338 & 8 & 3 & $59.8 \%$ & $18.2,80.2$ \\
\hline $46-50$ & 13792 & 84 & 10 & 274 & 7 & 4 & $76.2 \%$ & $48.4,89.0$ \\
\hline $51-55$ & 11369 & 72 & 12 & 288 & 2 & 1 & $8.8 \%$ & $0.0,77.6$ \\
\hline $56-60$ & 7381 & 27 & 2 & 218 & 1 & 0 & $20.3 \%$ & $0.0,89.2$ \\
\hline$>60$ & 14439 & 39 & 9 & 454 & 3 & 2 & $59.1 \%$ & $0.0,87.4$ \\
\hline Total & 304230 & 4980 & 243 & 6526 & 1027 & 320 & $89.6 \%$ & $88.9,90.2$ \\
\hline
\end{tabular}

${ }^{\$} \mathrm{CI}$, Confidence interval. For sub region-stratified descriptions ${ }^{[50]}$.

Table 3: $\quad$ Case fatality of smallpox by different vaccination status in Madras, India, during 1960s

\begin{tabular}{|c|c|c|c|c|c|c|}
\hline \multirow[t]{2}{*}{ Vaccination status } & \multicolumn{3}{|c|}{ Ordinal type $\$$} & \multicolumn{3}{|l|}{ Total } \\
\hline & Cases & Deaths & Case fatality & Cases & Deaths & Case fatality \\
\hline Unvaccinated & 1296 & 478 & 36.9 & 1453 & 620 & 42.7 \\
\hline Primary vaccination ${ }^{\dagger}$ & 2302 & 76 & 3.3 & 3266 & 770 & 23.6 \\
\hline Revaccination $^{\#}$ & 75 & 0 & 0.0 & 132 & 4 & 3.0 \\
\hline
\end{tabular}

${ }^{\$}$ Clinical classification of smallpox which is most common type in Madras ${ }^{[16]} .{ }^{\dagger}$ Primary vaccination only. ${ }^{\#}$ Evidence of primary vaccination and revaccination scars.

Although we obviously have to ignore the underlying population structures, we can clearly see that the majority of individuals who received primary vaccination must have been protected for a few decades ${ }^{[37,48]}$. Table 2 shows how the direct effectiveness of vaccination decreases over age, clarifying age-stratified estimates of the direct effectiveness. In a recent study, using similar records, the expected median duration of protection was estimated to be 11.7-28.4 years after primary vaccination ${ }^{[49]}$. More insight into the effect of waning immunity can be obtained by comparing the case fatalities of vaccinated and unvaccinated cases over $\operatorname{age}^{[50]}$. Given a similar data, Greenwood described that 'evidently, the advantage of the vaccinated brought out by such a table cannot be due to a fortuitous concurrence of age and vaccination groupings ${ }^{, 51]}$. Figure 4 shows the case fatality among vaccinated individuals slowly increasing but never reaching the corresponding value of unvaccinated cases. A statistical analysis, based on an outbreak in Liverpool, $1902-3^{[52,53]}$, led to a half-life of partial protection against death of 49.2 years (95\% CI: 42.0, 57.3).

Whereas the vaccine-derived protection against infection seems to have been lost after a few decades, a considerable fraction of vaccinees appears to have been protected throughout life against dying from smallpox ${ }^{[52,53]}$. However, as outbreaks of smallpox were not uncommon when these observations were made, vaccinated individuals may have experienced infections before the outbreak which may have boostered their immunity. Thus, Nishiura and Eichner confirmed the similar long-lasting partial immunity based on the epidemic records in Australia where booster events were much less frequent than in other countries ${ }^{[54]}$. An additional line of evidence comes from recent laboratory studies on humoral immune responses that also support the concept of a long-lasting residual (partial) protection ${ }^{[55-57]}$. In the event of a bioterrorist attack, this fact could significantly decrease the individual burden of disease ${ }^{[58]}$.

Effects on contagiousness and duration of disease: Partial protection may not only have reduced the vaccinees' susceptibility and their probability to develop severe disease, but it could also have reduced the degree and duration of contagiousness which again would have modified the transmission dynamics (Fig. $5)^{[59]}$. Rao favored a reduced contagiousness among vaccinated cases, based on observations in intra-household transmission ${ }^{[27]}$. He demonstrated that on average $67.4 \%$ fewer susceptible intra-household contacts were infected by vaccinated cases than by unvaccinated ones (10/499 vs. $40 / 650$ transmissions). If the contacts had been vaccinated before, the reduction was $74.8 \%$ (2/421 vs. $11 / 583$ transmissions). Some evidence for an effect of prior vaccination on the duration of infectiousness was obtained in an outbreak 
in Dalian, China, in $1920-1^{[60]}$ : The average symptomatic period was 15.8 days $(n=179)$ for vaccinated and 18.3 days $(n=40)$ for unvaccinated cases, respectively, indicating a reduction of $13.7 \%$. Observations in another outbreak in Dalian, 1933-4 showed mean symptomatic periods of 15.5 and 30.1 days for vaccinated $(n=448)$ and unvaccinated $(n=39)$ cases, respectively, demonstrating a reduction of $48.5 \%{ }^{[61]}$. Toyoda suggested that the difference of symptomatic periods may have originated from residual (partial) protection among vaccinated cases ${ }^{[60]}$.

\section{Vaccination schemes}

Revaccination: When it became apparent that the vaccination effects waned over time, repeated vaccinations were performed to renew the vaccinees' immunity and unscheduled revaccination became a common countermeasure whenever new cases occurred in a community ${ }^{[16,37]}$. The first compulsory vaccinations and revaccinations were introduced in Germany during the mid-19th century, achieved by demanding a vaccination certificate from children who entered primary school ${ }^{[9,62]}$. Compulsory and scheduled revaccinations widely stimulated scientific discussions on the benefit of vaccination ${ }^{[63,64]}$, but remained very uncommon in the UK until the beginning of 20th century ${ }^{[9,23]}$. Scheduled revaccination became widely accepted and reinforced only after the accumulation of sufficient observations that revaccinated cases were infected less often and had much milder manifestations ${ }^{[7,21,37]}$. Since the intervals from primary vaccination to revaccinations and the number of revaccinations varied strongly within and between countries $^{[37]}$, analytical evaluations are very difficult and of limited precision, although there is much circumstantial evidence of the benefits of revaccination. Crude estimates of the increased partial protection against case fatality could frequently be confirmed as can be seen from data collected in Madras during the 1960s (Table 3) ${ }^{[16]}$.

\section{Post-exposure vaccination: Post-exposure} vaccinations have been reported since the late 19th century in the $\mathrm{UK}^{[50,52]}$. Although many records give the number of cases and the delay between post-exposure vaccination and onset of symptoms (which starts with fever), all these reports lacked a denominator, i.e. the total number of people vaccinated after exposure ${ }^{[65,66]}$ and none of them compared the group receiving post-exposure vaccinations with an exposed group of unvaccinated individuals. Thus, the protective effect of post-exposure vaccination still remains unclear ${ }^{[66]}$. Based on the observations of several outbreaks, Lyons and Dixon stated that successful vaccination during the first seven days after exposure would almost always prevent the disease, that vaccination during the following three days would modify the eruption and that vaccination during the last four days would merely add to the patient's troubles ${ }^{[67]}$. Part of this suggestion was later confirmed by comparing the frequency of cases, dichotomized at 10 days after exposure ${ }^{[68]}$.
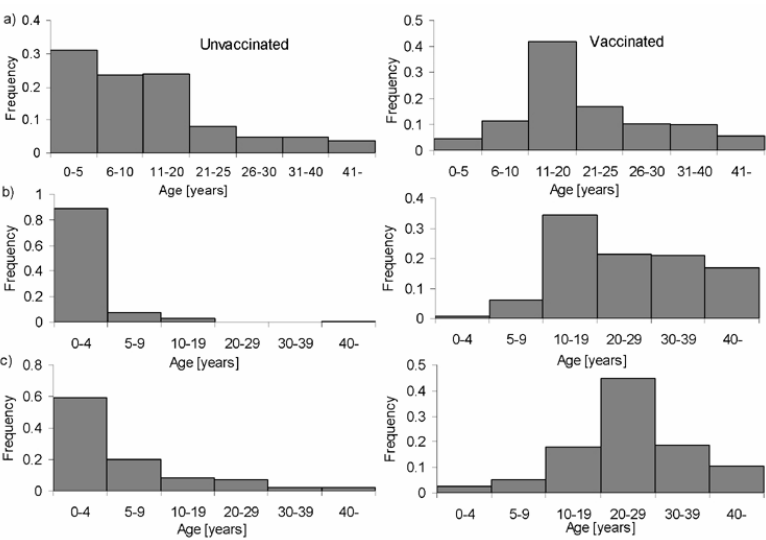

Fig. 3: Comparisons of the frequency of smallpox cases by age and vaccination in three outbreaks during 19th and 20th centuries.a) London $(\mathrm{n}=10403)$ during $1870 \mathrm{~s}^{[63]}$, b) Leipzig $(\mathrm{n}=688)$ during $1860 \mathrm{~s}^{[94]}$ and $\left.\mathrm{c}\right)$ Madras, India $(n=6932)$ during $1960 \mathrm{~s}^{[16]}$

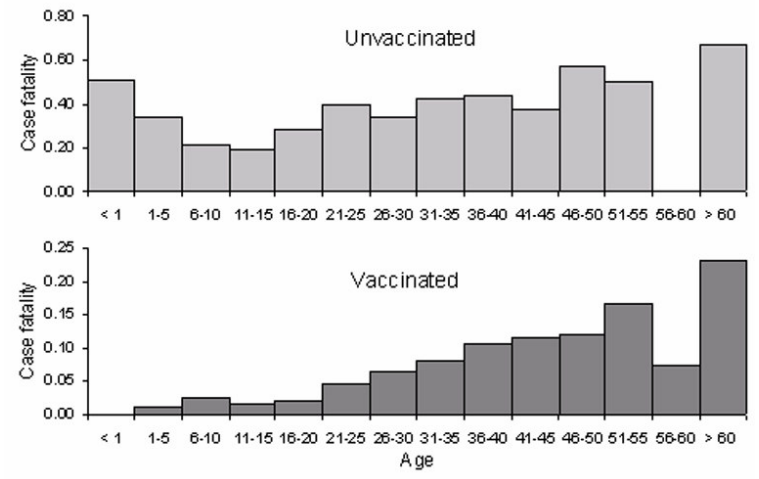

Fig. 4: Comparisons of case fatality of smallpox by age and vaccination in Sheffield, 1887-8 ( $\mathrm{n}=$ 310,756 ). For stratified number of cases and deaths, see Table $2^{[50]}$

Results of a recent statistical model indicated that vaccination up to 3.2 days $(95 \% \mathrm{CI}, 2.9,3.6)$ after exposure may protect against disease ${ }^{[69]}$ and a recent Delphi analysis suggested that the post-exposure vaccine efficacy could be $80-93 \%$ during the first 3 days after the exposure and $2-25 \%$ thereafter $^{[70]}$.

With regard to evaluation of partial effects among vaccinated individuals, it was suggested that the residual immunity due to prior vaccinations lasted for a long time (sometimes lifelong) and thus, that partial protection due to vaccination may have influenced the probability of death or severe disease rather than the post-exposure vaccination ${ }^{[66]}$. Figure 6 shows the probability of severe manifestation in relation to the time interval between post-exposure vaccination and onset of fever, considering only cases who had not received vaccination before exposure ${ }^{[52,66]}$. Results of a logit model suggest that a growing interval between vaccination and onset of disease significantly reduced the risk of severe disease (Nishiura and Eichner, 
submitted): cases who were vaccinated more than 5 days before onset had less than half the risk of developing serious manifestations ${ }^{[52]}$.

Ring vaccination: A surveillance-containment measure during the Eradication Programme, ring vaccination, denotes the vaccination and monitoring of all susceptible individuals in a prescribed area around one or several index cases ${ }^{[71]}$. Especially since the 1960 s, ring vaccination, in addition to other public health measures, was considered to be more effective than mass vaccination alone ${ }^{[72]}$. Ring vaccination was introduced and evaluated mainly in West and Central Africa and in Asia ${ }^{[73]}$ where it was frequently combined with case isolation and special measures aimed to prevent transmission in hospitals ${ }^{[74]}$. Although it has been difficult to exclude confounders and to evaluate the net effectiveness of ring vaccination precisely, technical discussions suggested benefits of field-based practice and compared ring vaccination with mass vaccinations $^{[75,76]}$. Observations during the 1960-70s in India support the potential effectiveness of ring vaccination: After halting a 10 year series of mass vaccination campaigns which had failed to eliminate transmission, public health workers started to visit each village and to vaccinate the villagers wherever they found at least one case. This resulted in eradication within 1.5 years $^{[77]}$. Although the impact of previous vaccination cannot be separated, the finding supports the potential effectiveness of ring vaccination in localized outbreaks ${ }^{[77]}$. Mathematical models have claimed critical importance of contact tracing if we rely on ring vaccination alone ${ }^{[78,79]}$.

Future challenges: Although (or maybe because) smallpox vaccination has the longest history of all vaccinations, we lack precise epidemiologic estimates of its effectiveness. Vaccination practice continually evolved and many places experienced vaccinations with various strains over time ${ }^{[2]}$. Several new vaccines that may be more efficacious and less toxigenic have lately been proposed ${ }^{[80,81]}$, but even simple population-based comparisons have to rely on laboratory studies in the absence of smallpox. Although statistical evidence is weak, it can be stated with certainty that smallpox vaccines prevented infection for a few decades after primary vaccination and that vaccinated individuals had the benefit of a longer lasting partial protection when they contracted the disease. After all, smallpox was eradicated by combining effective vaccines with other control measures ${ }^{[3,4]}$. There has been a considerable debate on the re-introduction of mass vaccination and containment strategies in the event of a bioterrorist attack, but mass vaccination prior to an attack is currently not recommended ${ }^{[82,83]}$. One of the biggest problems we are currently faced with may be that residual immunity is gradually lost among vaccinated individuals and that unvaccinated cohorts further add to the accumulating pool of susceptible ${ }^{[84]}$. Mathematical models, stressing important aspects of the transmission dynamics (i.e., spatial spread ${ }^{[85]}$, contact tracing ${ }^{[86]}$ and vaccination schemes ${ }^{[78,79,87-89]}$, have been used to study responses to a simulated smallpox attack, but none of them explicitly incorporated all the protective effects of vaccination. Incorporating partial protection in these

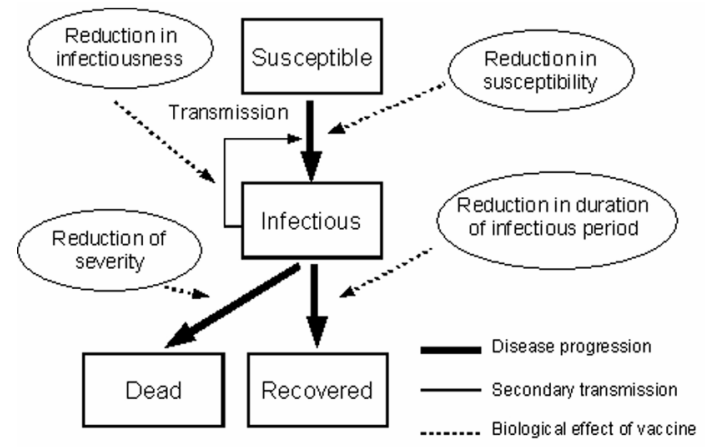

Fig. 5: Population dynamics of smallpox among vaccinated individuals. Even though vaccinated individuals can be infected, partial protection provides individual or population benefits. Biological actions, conferred by vaccination, are shown with broken arrows

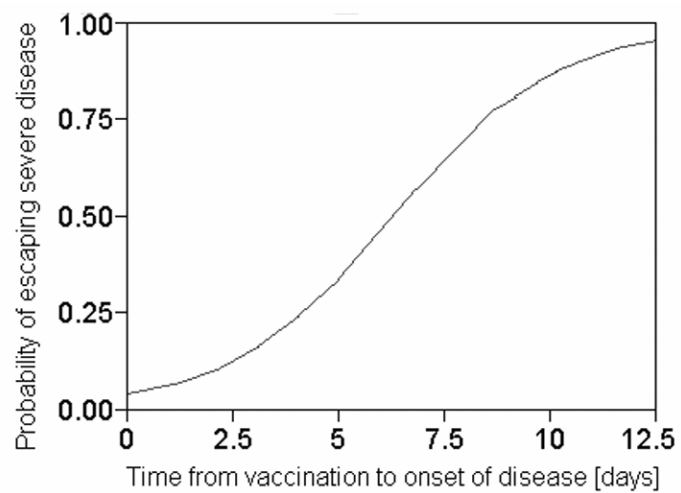

Fig. 6: Partial protection induced by post-exposure vaccination. Gradual increase of the probability of escaping severe manifestation is shown in relation to the time from vaccination to onset of the disease (For original descriptions of the data ${ }^{[52,66]}$ )

models may have a major impact on the results, especially when targeted interventions that strongly rely on typical symptoms are considered. Confronted with the huge uncertainties and with the necessity to rely on laboratory evidence, appropriate preparedness plans for countermeasures using vaccination must be based on the best available evidence.

\section{ACKNOWLEDGEMENT}

This work was supported in part by the Banyu Life Science Foundation International, the DG Sanco Project MODELREL, EU Project INFTRANS and the German Ministry of Health and Social Security, BMGS. 


\section{REFERENCES}

1. Arita, I., 1979. Virological evidence for the success of the smallpox eradication programme. Nature., 279: 293-298.

2. Fenner, F., D.A. Henderson, I. Arita, Z. Jezek and I.D. Ladnyi, 1988. Smallpox and its Eradication. World Health Organization, Geneva.

3. Breman, J.G. and I. Arita, 1980. The confirmation and maintenance of smallpox eradication. N. Engl. J. Med., 303: 1263-1273.

4. Henderson, D.A., T.V., Inglesby, J.G. Bartlett, et al., 1999. Smallpox as a biological weapon: medical and public health management. Working Group on Civilian Biodefense. JAMA., 281: 2127-2137.

5. Susser, E. and M. Bresnahan, 2001. Origins of epidemiology. Ann. N.Y. Acad. Sci., 954: 6-18.

6. Nishiura, H., 2006. Smallpox during pregnancy and maternal outcomes. Emerg. Infect. Dis., 12: 1119-1121.

7. Simon, J., 1887. Public Health Reports / Sanitary Institute of Great Britain. Offices of the Sanitary Institute, London.

8. Wallace, A.R., 1898. Vaccination a delusion: its penal enforcement a crime proved by the official evidence in the reports of the Royal Commission. Swan Sonnenschein, London.

9. Hennock, E.P., 1998. Vaccination policy against smallpox, 1835-1914: a comparison of England with Prussia and Imperial Germany. Soc. Hist. Med., 11: 49-71.

10. Jenner, E., 1798. An Inquiry into Cause and Effects of the Variolae Vaccinae, a Disease Discovered in Some of the Western Countries of England, Particularly Gloucestershire and Known by the Name of Cow Pox. Sampson Low, London.

11. Goodall, A.L., 1942. Some statistical notes on vaccination. Glasgow. Med. J., 138: 143-145.

12. Baxby, D., 1977. The origins of vaccinia virus. J. Infect. Dis., 136: 453-455.

13. Cockburn, W.C., R.M. Cross, A.W. Downie et al., 1957. Laboratory and vaccination studies with dried smallpox vaccines. Bull.WHO., 16: 63-77.

14. Haber, M., 1999. Estimation of the direct and indirect effects of vaccination. Stat. Med., 18: 2101-2109.

15. World Health Organization, 1964. WHO Expert Committee on Smallpox: First Report. WHO Tech. Rep. Ser., 283: 1-37.

16. Rao, A.R., 1972. Smallpox. Kothari Book Dept, Bombay.

17. Rosenthal, S.R., M. Merchlinsky, C. Kleppinger and K.L. Goldenthal, 2001. Developing new smallpox vaccines. Emerg. Infect. Dis., 7: 920-926.
18. Phelps, A., A.J. Gates, M. Hillier, L. Eastaugh and D.O. Ulaeto, 2005. Comparative efficacy of replicating smallpox vaccine strains in a murine challenge model. Vaccine., 23: 3500-3507.

19. Thomson, J., 1820. An account of the varioloid epidemic which has lately prevailed in Edinburgh and other parts of Scotland: with observations on the identity of chicken-pox with modified small-pox in a letter to Sir James M'Grigor. Longman, Hurst, Rees, Orme and Brown, London.

20. Bousquet, J.B., 1833. Traité de la vaccine et des éruptions varioleuses ou varioliformes. Ouvrage rédigé sur la demande du gouvernement. chez J.-B. Baillière, Paris (in French).

21. Edwardes, E.J., 1892. Vaccination and small-pox in England and other countries. Churchill, London.

22. Jenner, E. and General Board of Health, Great Britain., 1857. Papers relating to the history and practice of vaccination. George Edward Eyre and William Spottiswoode for HMSO, London.

23. Lotz, T., 1880. Pocken und vaccination. Bericht über die Impffrage, erstattet im Namen der schweizerischen Sanitätskommission an den schweizerischen Bundersrath. Benno Schwabe, Basel (in German).

24. Nishiura, H., K. Dietz and M. Eichner, 2006. The earliest notes on the reproduction number in relation to herd immunity: Theophil Lotz and smallpox vaccination. J. Theor. Biol., in press (doi:10.1016/j.jtbi.2006.01.012).

25. Greenwood, M. and G.U. Yule, 1914-15. The statistics of anti-typhoid and anti-cholera inoculations and the interpretation of such statistics in general. Proc. R. Soc. Med., 8: 113-189.

26. Cross, J., 1820. A history of the variolous epidemic which occurred in Norwich in the year 1819 and destroyed 530 individuals; with an estimate of the protection afforded by vaccination and a review of past and present opinions upon chicken-pox and modified smallpox. Burgess and Hill, London.

27. Rao, A.R., E.S. Jacob, S. Kamalakshi, S. Appaswamy and Bradbury, 1968. Epidemiological studies in smallpox. A study of intrafamilial transmission in a series of 254 infected families. Ind. J. Med. Res., 56: 1826-1854.

28. Heiner, G.G., N. Fatima and F.R. Jr. McCrumb, 1971. A study of intrafamilial transmission of smallpox. Am. J. Epidemiol., 94: 316-326.

29. Mukherjee, M.K., J.K. Sarkar and A.C. Mitra, 1974. Pattern of intrafamilial transmission of smallpox in Calcutta, India. Bull. WHO., 51: 219-225.

30. de Azeredo Costa, E. and L. Morris, 1975. Smallpox epidemic in a Brazilian community. Am. J. Epidemiol., 101: 552-561. 
31. de Carvalho Filho, E.S., L. Morris, A.L. de Lemos, J. Ponce de Leon, A. Escobar and O.J. da Silva, 1970. Smallpox eradication in Brazil, 1967-69. Bull. WHO., 43: 797-807.

32. de Quadros, C.C., L. Morris, E.A. Da Costa, N. Arnt and C.H. Tigre, 1972. Epidemiology of variola minor in Brazil based on a study of 33 outbreaks. Bull. WHO., 46: 165-171.

33. Orenstein, W.A., R.H. Bernier and A.R. Hinman, 1998. Assessing vaccine efficacy in the field. Further observations. Epidemiol. Rev., 10: 212-241.

34. Thompson, D. and W. Foege, 1968. Faith Tabernacle smallpox epidemic. Abakaliki, Nigerial. World Health Organization (WHO/SE/68.3), Geneva.

35. Eichner, M. and K. Dietz, 2003. Transmission potential of smallpox: estimates based on detailed data from an outbreak. Am. J. Epidemiol., 158: 110-117.

36. Fox, J.P., L. Elveback, W. Scott and L. Gatewood, 1971. Herd immunity: Basic concept and relevance to public health immunization practices. Am. J. Epidemiol., 94: 170-189.

37. Dixon, C.W., 1962. Smallpox. Churchill, London.

38. Fine, P.E.M., 1993. Herd immunity: History, theory, practice. Epidemiol. Rev., 15: 265-302.

39. Farr, W., 1839-40. Second Report. In: Annual report of the Registrar-General of births, deaths and marriages in England. H.M.S.O., London.

40. Arita, I., J. Wickett and F. Fenner, 1986. Impact of population density on immunization programmes. $\mathbf{J}$. Hyg., 96: 459-466.

41. Anderson, R.M. and R.M. May, 1985. Vaccination and herd immunity to infectious diseases. Nature., 318: 323-329.

42. Anderson, R.M. and R.M. May, 1990. Immunisation and herd immunity. Lancet., 335: 641-645.

43. World Health Assembly, 1959. Handbook of resolutions and decisions of the twelfth World Health Assembly and Executive Board. World Health Organization (12.54), Geneva.

44. Gani, R. and S. Leach, 2001. Transmission potential of smallpox in contemporary populations. Nature., 414: 748-751.

45. O'Neill, P.D. and N.G. Becker, 2001. Inference for an epidemic when susceptibility varies. Biostatistics., 2: 99-108.

46. Elkington, J.S.C., 1904. Outbreak of smallpox in Launceston. Parliament of Tasmania Report No. 47, Hobart.

47. Iguchi, J., 1929. A report on prevention of smallpox. Institute of Public Health, Japanese Ministry of Interior, Tokyo (in Japanese).
48. Arita, I., 2002. Duration of immunity after smallpox vaccination: a study on vaccination policy against smallpox bioterrorism in Japan. Jpn. J. Infect. Dis., 55: 112-116.

49. Nishiura, H., M. Schwehm and M. Eichner, 2006. Still protected against smallpox? Estimation of the duration of vaccine-induced immunity against smallpox. Epidemiology., 17: in press (doi:10.1097/01.ede.0000229196.41862.c2).

50. Barry, F.W., 1889. Report on an epidemic of small-pox at Sheffield, during 1887-88. Local Government Board, London.

51. Greenwood, M., 1930. The vaccination problem. J. R. Stat. Soc., 93: 233-270.

52. Hanna, W., 1913. Studies in small-pox and vaccination. John Wright, Bristol.

53. Eichner, M., 2003. Analysis of historical data suggests long-lasting protective effects of smallpox vaccination. Am. J. Epidemiol., 158: 717-723.

54. Nishiura, H. and M. Eichner, 2006. Estimation of the duration of vaccine-induced residual protection against severe and fatal smallpox based on secondary vaccination failure. Infection., 34: in press (doi: 10.1007/s15010-006-6603-5).

55. Hammarlund, E., M.W. Lewis, S.G. Hansen, et al., 2003. Duration of antiviral immunity after smallpox vaccination. Nat. Med., 9: 1131-1137.

56. Gallwitz, S., T. Schutzbank, R.L. Heberling, S.S. Kalter and J.E. Galpin, 2003. Smallpox: Residual antibody after vaccination. J. Clin. Microbiol., 41: 4068-4070.

57. Crotty, S., P. Felgner, H. Davies, J. Glidewell, L. Villarreal and R. Ahmed, 2003. Cutting edge: Long-term B cell memory in humans after smallpox vaccination. J. Immunol., 171: 4969-4973.

58. Nishiura, H. and I.M. Tang, 2004. Modeling for a smallpox-vaccination policy against possible bioterrorism in Japan: the impact of long-lasting vaccinal immunity. J. Epidemiol., 14: 41-50.

59. Simon, C.P. and J.S. Koopman, 2001. Infection transmission dynamics and vaccination program effectiveness as a function of vaccine effects in individuals. In: S. Blower, C. Castillo-Chavez, P. van den Driessche and A.A. Yakubu (Eds) Mathematical Approaches for Emerging and Reemerging Infectious Diseases : Models, Methods and Theory. Springer-Verlag, New York, 143-155.

60. Toyoda, T., 1923. Smallpox research. Part II. Findings based on 516 smallpox cases with special reference to hemorrhagic type and variola sine exanthemate. Tokyo Med. J., 2333: 1-12 (in Japanese). 
61. Yamadori, K., 1935. Epidemiologic and clinical observations of 599 smallpox cases in the outbreak of Dalian. J. Jpn. Assoc. Infect. Dis., 10: 61-73 (in Japanese).

62. Hering, E., 1839. Über Kuhpocken an Kühen. Ebner \& Seubert, Stuttgart (in German).

63. Gayton, W., 1885. The value of vaccination as shown by an analysis of 10,403 cases of smallpox. Gillett \& Henty, London.

64. Biggs, J.T., 1912. Leicester: sanitation versus vaccination its vital statistics compared with those of other towns, the army, navy, Japan and England and Wales. The National Anti-Vaccination League, London.

65. Amako, T., 1909. Studien über die Variolaepidemie in Kobe. Arch. schiffs u. tropenhyg., 13: 409-421.

66. Mortimer, P.P., 2003. Can postexposure vaccination against smallpox succeed? Clin. Infect. Dis., 36: 622-629.

67. Lyons, J. and C.W. Dixon, 1953. Smallpox in the industrial Pennines, 1953. Med. Officer., 26: 307-310.

68. Mack, T.M., D.B. Thomas, A. Ali and M. Muzaffar Khan, 1972. Epidemiology of smallpox in West Pakistan. I. Acquired immunity and the distribution of disease. Am. J. Epidemiol., 195: 157-168.

69. Eichner, M. and M. Schwehm, 2004. Smallpox. A vulnerable specter. Epidemiology., 15: 258-261.

70. Massoudi, M.S., L. Barker and B. Schwartz, 2003. Effectiveness of postexposure vaccination for the prevention of smallpox: results of a delphi analysis. J. Infect. Dis., 188: 973-976.

71. Foege, W.H., J.D. Millar and J.M. Lane, 1971. Selective epidemiologic control in smallpox eradication. Am. J. Epidemiol., 94: 311-315.

72. Henderson, D.A., 1972. Epidemiology in the global eradication of smallpox. Int. J. Epidemiol., 1: 25-30.

73. Foege, W.H., J.D. Millar and D.A. Henderson, 1975. Smallpox eradication in West and Central Africa. Bull. WHO., 52: 209-222.

74. Arita, I., E. Shafa and A. Kader, 1970. Role of hospital in smallpox outbreak in Kuwait. Am. J. Public. Health., 60: 1960-1966.

75. Kaplan, E.H. and L.M. Wein, 2003. Smallpox eradication in West and Central Africa: surveillance-containment or herd immunity? Epidemiology., 14: 90-92.

76. Enserink, M., 2003. Bioterrorism. New look at old data irks smallpox-eradication experts. Science., 299: 181.

77. Arita, I., 2001. A Scenario for Polio Eradication. In F. Brown (ed): Progress in Polio Eradication: Vaccination Strategies for the End Game. Karger, Developments in Biological, Basel, 105: 33-40.

78. Kretzschmar, M., S. van den Hof, J. Wallinga and J. van Wijngaarden, 2004. Ring vaccination and smallpox control. Emerg. Infect. Dis., 10: 832-841.
79. Porco, T.C., K.A. Holbrook, S.E. Fernyak, D.L. Portnoy, R. Reiter and T.J. Aragon, 2004. Logistics of community smallpox control through contact tracing and ring vaccination: a stochastic network model. BMC. Public. Health., 4: 34.

80. Kidokoro, M., M. Tashiro and H. Shida, 2005. Genetically stable and fully effective smallpox vaccine strain constructed from highly attenuated vaccinia LC16m8. Proc. Natl. Acad. Sci. USA., 102: 4152-4157.

81. Otero, M., S.A. Calarota, A. Dai, A.S. De Groot, J.D. Boyer and D.B. Weiner, 2006. Efficacy of novel plasmid DNA encoding vaccinia antigens in improving current smallpox vaccination strategy. Vaccine., in press (doi:10.1016/j.vaccine.2005.08.010).

82. Pennington, H., 2003. Smallpox and bioterrorism. Bull. WHO., 81: 762-767.

83. Centers for Disease Control and Prevention (CDC), 2004. Advisory Committee on Immunization Practices (ACIP) Statement on Smallpox Preparedness and Vaccination. Emergency Preparedness \& response. CDC, Atlanta.

84. Arita, I., 2005. Smallpox vaccine and its stockpile in 2005. Lancet Infect. Dis., 5: 647-652.

85. Grais, R.F., J.H. Ellis and G.E. Glass, 2003. Forecasting the geographical spread of smallpox cases by air travel. Epidemiol. Infect., 131: 849-857.

86. Eichner, M., 2003. Case isolation and contact tracing can prevent the spread of smallpox. Am. J. Epidemiol., 158: 118-128.

87. Kaplan, E.H., D.L. Craft and L.M. Wein, 2002. Emergency response to a smallpox attack: the case for mass vaccination. Proc. Natl. Acad. Sci. USA., 99: 10935-10940.

88. Halloran, M.E., I.M. Jr. Longini, A. Nizam and Y. Yang, 2002. Containing bioterrorist smallpox. Science., 298: 1428-1432.

89. Bozzette, S.A., R. Boer, V. Bhatnagar, J.L. Brower, E.B. Keeler, S.C. Morton and M.A. Stoto, 2003. A model for a smallpox-vaccination policy. N. Engl. J. Med., 348: 416-425.

90. Feemster, R.F., G.W. Anderson, R.F. Burns and H.M. De Wolfe, 1932. The recent smallpox outbreak in Fitchburg. N. Engl. J. Med., 207: 82-87.

91. Wunderlich, C.A., 1855. Handbuch der Pathologie und Therapie. Ebner \& Seubert, Stuttgart (in German).

92. Steinbrenner, C.C., 1846. Traité sur la vaccine ou recherches historiques et critiques sur les résultats obtenus par les vaccinations et revaccinations, depuis le commencement de leur emploi universel jusqu'à nos jours, ainsi que sur les moyens proposés pour en faire un préservatif aussi puissant que possible contre la variola. Labé, Paris (in French).

93. Haeser, H., 1854. Die Vaccination und ihre neuesten Gegner. Hertz, Berlin (in German).

94. Wunderlich, C.A., W. Roser and E. Wagner, 1869. Archiv der Heilkunde. Wigand, Leipzig (in German). 